\title{
Ecological Systems and Complexity Theory: Toward an Alternative Model of Accountability in Education
}

\author{
EILEEN S. JOHNSON \\ Oakland University (USA)
}

\begin{abstract}
The call for accountability within education has led to the increased examination of the academic achievement of students across the nation. Too often, however, schools and school districts are scrutinized by means of overly simplistic linear models that fail to consider the complexity of interactions that result in student achievement. This paper postulates that student achievement is instead best understood as a developmental outcome that emerges as a result of interactions among layers within a complex system. Organizations such as schools can be modeled using Bronfenbrenner's ecological systems and analyzed using complexity theory as an appropriate and useful alternative to the linear models that often form the basis of educational research and policy. Key elements of both Bronfenbrenner's ecological-contextual theory and complexity are explained and applied at the level of an individual school.
\end{abstract}

There has been a growing recognition of the importance of context in understanding various aspects of education (Phillips \& Burbules, 2000), and systems approaches to understanding change have become increasingly common. Yet, the simple linear algorithm implicit in current policy such as the Adequate Yearly Progress provision of No Child Left Behind (U.S. Department of Education, 2002) fails to take into account the complex and dynamic nature of education and represents an inappropriate oversimplification of educational outcomes and their measurement. 
This article postulates that the ecological systems model of Urie Bronfenbrenner represents a useful theoretical framework for understanding the processes and interactions involved in student achievement, and that the dynamic, non-linear changes within these systems can be effectively understood by applying the mathematical models of complexity theory.

\section{Ecological Systems Theory}

Bronfenbrenner developed his ecological systems theory in an attempt to define and understand human development within the context of the system of relationships that form the person's environment. His definition (1986) of the theory is as follows:

The ecology of human development is the scientific study of the progressive, mutual accommodation throughout the life course between an active, growing human being and the changing properties of the immediate settings in which the developing person lives. [This] process is affected by the relations between these settings and by the larger contexts in which the settings are embedded (p. 188).

According to Bronfenbrenner's initial theory (1989), the environment, is comprised of four layers of systems which interact in complex ways and can both affect and be affected by the person's development. He later added a fifth dimension that comprises an element of time (Bronfenbrenner, 1995). This theory can be extended to model the development of an organization as well, and is particularly appropriate for describing the complex systems of a school district or even of an individual school. Each of the four system layers are described below, and an example of a working model of the ecological context of an individual school is depicted in Figure 1.

\section{Microsystem}

The microsystem is defined as the pattern of activities, roles, and interpersonal relationships experienced by a developing person in a particular setting with particular physical and material features and containing other persons with distinctive characteristics of temperament, personality, and systems of belief (Bronfenbrenner, 1995, p. 227). In other words, this layer forms a set of structures with which a person has direct contact, and the influences between the developing person and these structures are bidirectional. The person influences and is influenced by the microsystem. If this theory is extended from human development to organizational development, and an individual school is the unit of interest, the microsystem of the school would include students, parents and family members, administration, teachers, and the surrounding community.

\section{Mesosystem}

The mesosystem, simply stated, comprises the linkages between microsystems (Bronfenbrenner, 1995, p. 227). Just as the direction of influence between the school and each structure within the microsystem is bi-directional, the mesosystem involves bidirectional influences between these various structures. An example of the mesosystem of an individual school can be seen in the interactions and dynamics between two of its 
microsystems, students and parents. Parental expectations regarding the academic and extra-curricular success of their children can often create a dynamic that directly and indirectly impacts the atmosphere and climate of the school. Unreasonably high expectations and low tolerance for failure can create a dynamic between parent and child that is characterized by tension and fear. This dynamic impacts the school in various direct and indirect ways, including, for example, student behavior in the classroom resulting from such expectations, pressures to ensure their child's success placed on school personnel by the parent, or an attempt by school personnel to shield students from such parental pressures by restricting the amount of information that is communicated regarding student achievement.

\section{Exosystem}

The exosystem represents the larger social system, and encompasses events, contingencies, decisions, and policies over which the developing person has no influence. The exosystem thus exerts a unidirectional influence that directly or indirectly impacts the developing person. The exosystem of an individual school might be comprised of such structures as, for example, state regulations, local economics, federal mandates, and local disasters.

\section{Macrosystem}

The macrosystem can be thought of as the "social blueprint" of a given culture, subculture, or broad social context and consists of the overarching pattern of values, belief systems, lifestyles, opportunities, customs, and resources embedded therein. This system is generally considered to exert a unidirectional influence upon not only the person but the micro-, meso-, and exosystems as well. The macrosystem of an individual school is embodied not only in the cultural, political, social, and economic climate of the local community, but that of the nation as a whole.

\section{Chronosystem}

Although not one of the four system layers per se, the chronosystem represents a timebased dimension that influences the operation of all levels of the ecological systems. The chronosystem can refer to both short- and long-term time dimensions of the individual over the course of a lifespan, as well as the socio-historical time dimension of the macrosystem in which the individual lives. The chronosystem of an individual school, therefore, may be represented by both the day-to-day and year-to-year developmental changes that occur in its student body, teaching staff, curricular choices, etc., as well as the overall number of years in operation (i.e., a newer school faces challenges and opportunities that differ from those of a school that has been in operation for a length of time). 


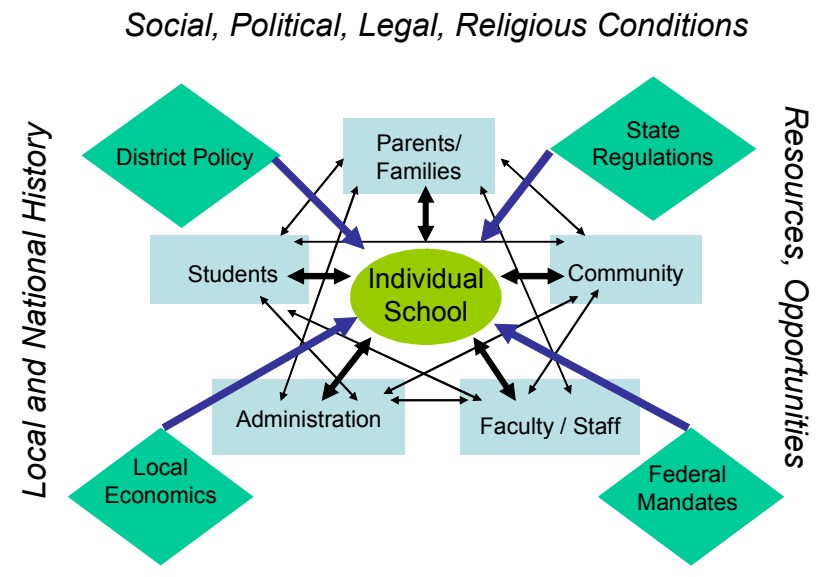

Cultural Customs, Beliefs, Values

Figure 1. A working model of the ecological context of an individual school

\section{Development in Context}

In addition to defining the ecological systems in which development takes place, Bronfenbrenner also emphasized the importance of context in human development. In order to model development or change within an individual, Bronfenbrenner built upon the work of Kurt Lewin (1935), who is credited as one of the first theorists to recognize the importance of interaction between the person and environment in describing human behavior. Development can be formulated as follows:

$$
D t=f(t-p)(P E)(t-p)
$$

Whereas the initial reformulation of Lewin's work resulted in the relatively simple equation, $D=f(P E)$ in which development (D) was considered to be a joint function (f) of the interaction between the person and the environment $(\mathrm{PE})$, this later revision introduces the element of time at which developmental outcomes are observed $(t)$ and the period(s) during which joint forces, emanating from the person and environment, operate to produce the outcome existing at the time of observation ( $t-p)$. Thus, the characteristics of a person at a given time in his or her life are a joint function of the characteristics of the person and of the environment over the course of the person's life up to the time of observation (Bronfenbrenner, 1989, p. 191). Similarly, the characteristics of a school, including the level of academic proficiency of its students, at any given point in time may be appropriately considered a joint function of the characteristics of the organization itself and of the environment, or ecological systems, over the entire course of the school's lifetime up to the time of observation. The basic idea contained in this formula is particularly important because its nonlinear property extends understanding of human- and organizational- development beyond mere additive functions to 
interaction effects and elements of both short- and long-term time observations and demonstrates the essence, if in a simplified form, of complexity theory.

\section{Theoretical Models}

Bronfenbrenner (1989) distinguishes between class-theoretical and field theoretical models of research. Class-theoretical models include what he terms social address models, personal attribute models (Bronfenbrenner \& Crouter, 1983), and person-context models; these are limited in that they provide little insight into processes that lead to particular outcomes. For example, social address models focus solely on the environment, placing developmental outcomes as a function of social characteristics such as family size, socio-economic status, etc. Similarly, personal attribute models focus only on the individual, placing developmental outcomes as primarily a function of characteristics of the person at an earlier age (e.g., reading ability at age 16 as a function of early experiences with phonological awareness at age 6). And although more informative than the previous models, the person-context model is still limited in focus. This model focuses on particular environmental characteristics that are seen as either risk or favorable factors for the development of particular outcomes in individuals with particular characteristics, but there is still an absence of investigation into the processes within the environment as well as the individual that lead to the outcome in question. For example, it may be useful to know that retention in any grade significantly increases the likelihood of dropping out of school among adolescent boys (National Association of School Psychologists [NASP], 2003). However, it would be far more informative to investigate the system-level processes associated with retention in grade as well as the interpersonal processes that lead to and result from retention in grade, and how these interact to create a propensity to drop out of school.

Instead, Bronfenbrenner advocated that research investigating human development should involve a field-theoretical approach in which the interaction of processes, person, and context are taken into consideration. Such research would focus on how developmental processes and outcomes vary as a joint function of the characteristics of the person as well as the environment, and their interactions over the course of time (Bronfenbrenner, 1989, p. 200). The underlying rationale for a process-person-context research model is applicable to organizational development as well, and is a useful model for understanding how developmental processes (e.g., teaching and learning) and outcomes (e.g., student achievement) vary as a joint function of the characteristics of not only the school itself but also those of the ecological systems or environment surrounding the school.

Currently, many methods of investigating the educational outcomes of individual schools fit the class-theoretical model and are based on linear algorithms that simplify and break down systems into isolated, component parts. The premise of such linear models is that inputs into the system will result in predictable outcomes. While appropriately predictive of some static, closed systems, these models fail to adequately predict the behavior of or capture the essence and emergent properties of complex 
systems involving three or more interacting components. Instead, methods of investigating developmental processes and outcomes for humans as well as organizations should be based on field theoretical models, and complexity theory offers an appropriate paradigm for understanding how changes in complex systems such as schools are often discontinuous and non-linear, and can lead abruptly to unexpected forms or states (Marshall \& Zohar, 1997).

\section{Complexity Theory}

Simply stated, the term 'complexity' has been defined as "order at the edge of chaos," a phrase attributed to Chris Langton (Waldrop, 1992), a computer scientist who studied artificial intelligence among other things. It is important, however, to distinguish between the colloquial definition of the word that implies randomness, confusion, or complete disorder from chaos in the modern scientific sense, which represents a specific kind of process from which a level of organization and order emerges that is difficult to discern and impossible to measure accurately for long-term prediction. Complex systems, i.e., systems that fit Bronfenbrenner's field theoretical model, balance precariously between stasis and entropy, and are constantly evolving and developing around this critical state. Examples include the stability of ecosystems, the rise and fall of civilizations, dips and subsequent recoveries of the stock market, heart rhythms, weather patterns, and even human consciousness (Marshall \& Zohar, 1997). Individual schools, embedded with the interactions and linkages of the four system layers, similarly balance precariously between a state of stasis and entropy, and seemingly minor changes in one element of a system layer can have a profound impact on the developmental processes and outcomes that are observed over time.

Schools and school systems meet the criteria, suggested by Davis and Summara (2006, pp. 5-6), as qualities necessary for a phenomenon to be classified as complex. To begin with, schools and school systems are self-organized in that their structure and function often spontaneously shift as the actions and reactions of autonomous agents become interlinked. Schools and school systems are also emergent in that, as entities, their continual evolution transcends the sum of the component parts. And yet, the communication that takes place within schools and school systems is often dependent upon the coherence of the short-range relationships within the system. These properties are most exemplified through Bronfenbrenner's microsystem. Furthermore, Schools and school systems usually demonstrate properties of a nested structure that is ambiguously bounded, exchanging energy and matter with surroundings in a manner described by Bronfenbrenner's mesosystem. Finally, schools and school systems, in the end, are also structure-determined as they adapt to changes within social, economic, and political contexts while internalizing, learning from, and evolving from systemic memory inherent in the system. These qualities are similar to Bronfenbrenner's exosystem and chronosystem. 


\section{Implications of Complexity Theory for Educational Research and Policy}

Currently, many educational philosophers and researchers focus on the complex nature of education and offer complexity theory as a useful research paradigm, a necessary means for understanding change within complex social systems (e.g., Davis, 2006; Radford, 2006). Yet, as early as 1993, Blackerby noted that

Nonlinear dynamics can be shown to model nonlinear phenomena better than linear models. While linear models may be considered acceptable approximations of some human [and organizational] behavior, they have no capacity to model transitions. Nonlinear models representing non-equilibrium dynamics are essential to illustrate system transitions such as from one stage of system development to another, from one paradigm to another, from one evaluation criteria to another (p. 88).

As far back as 1989, Crowell asserted that the challenge of the future in education is not the effective utilization of technology or even of accountability but, rather, the imperative need to recognize new conceptual models that are compatible with educational practices. In fact, the application of complexity theory to Bronfenbrenner's ecological systems as a conceptual model for school accountability and student learning outcomes may represent a best-fit model for developmental outcomes at the organizational level - in this case, the school. In 2003, Reilly noted that educational reform policy and modes of understanding cause-effect relationships within education are based on the untenable assumptions of linear proportionality, which has led to public perceptions of failure in education given the unparalleled investment of resources in recent years. Instead, Reilly pointed out that the same action in two apparently comparable systems can have quite different results due to differential sensitivity to initial conditions within various regions of each system (Reilly, 2003, p. 428). In other words, the interactions among multiple layers of the complex system that comprises the ecological context of a school could result in any number of unforeseen outcomes, and seemingly small changes or fluctuations in one system layer can potentially have farreaching consequences resulting in larger impacts in other systems layers. Thus, seemingly minor changes or fluctuations in, say, the economic condition of the community surrounding a school (exosystem) may have far-reaching long-term consequences for the achievement level of the school that may not be predictable or even evident in the absence of a dimension of time.

Many states currently consider the rate of change in achievement status among students to be partially indicative of adequate yearly progress. This change is often conceptualized using a relatively simple linear equation that calculates the target slope needed for a given school to achieve proficiency among $100 \%$ of its students by the year 2014 as required by NCLB. For example, if at the end of the 2003 school year, $80 \%$ of students in a given school scored in the proficient range on a state-mandated achievement test in a given area, then the target slope that would determine the necessary rate of increase in proficiency would be 1.82 . If $81 \%$ of the school's students reach the proficiency range in the following year, AYP as determined by this component will not have been met. Note, however, that there are several assumptions inherent within this formula. Not only is the school treated as a completely closed system - 
impervious to outside influences - which is an untenable assumption, this linear formula rests on assumptions of proportionality and additive functions. Instead, nonlinear equations can be used more effectively to map expected change values since factors such as time, development, interaction effects, energy input and loss, and measurement error can be accounted for, and upper- and lower-limit boundaries can theoretically be removed (Blackerby, 1993). For example, there are developmental periods at which achievement levels can be expected to fluctuate more than at others. Achievement among middle school students should vary more so than among students in lower grades due to the increased range of skills for which a student must demonstrate proficiency, increased variability in academic experiences, and countless differences in development and environment that tend to increase the variability among individuals during the early adolescent years.

The idea of a school as a complex system in which developmental processes and outcomes emerge from a complex interaction among systemic layers is consistent with what seems to be intuitively known by many educators - that the rate of academic achievement is not a simple monotonic function that increases toward absolute proficiency. Instead, any mathematical model for expected rate of change in academic achievement of a particular school must build the ecological systems of the school into the equation as parameters. The processes that link the layers or regions within the system can then be defined in terms of functions and feedback. For example, in the following equation, èt is the parameter difference between achievement at a previous and current time $(\mathrm{t})$ for all values of $\mathrm{t}$. The community parameter, kappa $(\kappa)$, acts as a scaling parameter (resources available, for example) while a family parameter, phi $(\phi)$, similarly acts as a scaling parameter (education level of the parents, for example), and gamma $(\gamma)$ is each individual student whose value is then added to a particular school's composite progress. In this way, the time element and assumptions of nonlinear development as well as positive and negative inputs from other layers within the system such as community and family are taken into consideration.

$$
\begin{aligned}
& -\kappa \phi 2 \mathrm{t}-\tau \\
& \Sigma(\dot{e} t=\gamma \text { et- } \tau-\phi \text { et- } \tau \text { e } \kappa 2)
\end{aligned}
$$

Furthermore, educational policy must move beyond class-theoretical models in which environmental or interpersonal factors are considered solely responsible for developmental outcome. Many state formulas for adequate yearly progress include a provision that requires specific subgroups (defined in terms of ethnicity, racial background, special needs, limited English proficiency, etc.) within a given school to achieve at the level indicated by the target slope in order for a school to be considered successful. However, this requirement relies on a class-theoretical model that fails to take into account specific processes or interactions involved in differential learning outcomes. Instead, a field-theoretical model may provide educators with insight into the interactions among layers within the complex system that have resulted in differential levels of achievement. 


\section{Conclusion}

Educational systems are complex, dynamic systems with multidirectional linkages and processes that interconnect the different layers within the system. As such, developmental processes and outcomes in the form of student achievement may be best understood using the constructs and methods of new sciences. There must be recognition as to the limitations of and faulty assumptions implicit in linear models that render them inappropriate at best, and potentially harmful as the basis for education policy, reform, and accountability efforts. While linear approximations of nonlinear phenomena are at times, the only viable option (Blackerby, 1993, p. 53), the challenge is to communicate understanding that continued reliance upon inappropriate linear models propagates misperceptions about student achievement and educational outcomes. Such misperceptions will continue to perpetuate accusations of misuse of resources, wasted tax dollars, and incompetence of public schools to educate students.

Future research efforts aimed at informing educational policy might focus on clarifying the multiple layers within the complex educational system using an ecological systems approach and drawing upon the concepts of complexity. Seeking a deeper understanding of changes in academic achievement within a given school, for example, might begin with a model of the sources of energy loss, points of bifurcation, and levels of initial sensitivity within the layers of the system. Additionally, investigating the impact of various systems on student achievement using complexity theory is a promising avenue for future research. While the mathematical models and the complex equations of complexity theory are difficult to understand, given the limitations of traditional approaches, it is necessary to move beyond metaphorical application of complexity theory if we are to better understand educational outcomes and to discern that which can be controlled from that which can not.

\section{References}

Blackerby, R. F. (1993). Application of chaos theory to psychological models. U.S. Performance Strategies Publications.

Bronfenbrenner, U. (1986). Recent advances in research on human development. In R. K. Silbereisen, K. Eyferth, \& G. Rudinger (Eds.), Development as action in context: Problem behavior and normal youth development (pp. 287-309). New York: Springer.

Bronfenbrenner, U. (1989). Ecological systems theory. Annals of child development, 6, 187-249.

Bronfenbrenner, U. (1995). Developmental ecology through space and time: A future perspective. In P. Moen \& G. H. Elder, Jr., (Eds.), Examining lives in context: Perspectives on the ecology of human development (pp. 619-647). Washington, DC: American Psychological Association.

Bronfenbrenner, U., \& Crouter, A. C. (1983). The evolution of environmental models in developmental research. In H. Mussen, Handbook of child psychology: Vol. I. History, theory, and methods (pp. 357414). New York: Wiley.

Crowell, S. (1989). A new way of thinking: the challenge of the future. Educational Leadership, 7(1), 144147.

Davis, B. (2006). Complexity and education: Vital simultaneities. Retrieved September 19, 2007 from http://www.quasar.ualberta.ca/cpin/davis_simultanaeities.pdf.

Davis, B., \& Sumara, D. (2006). Complexity and education: Inquiries into learning, teaching, and research. Mahway, NJ: Lawrence Erlbaum Associates. 
Lewin, K. (1935). A dynamic theory of personality. New York: Wiley.

Marshall, I. \& Zohar, D. (1997). Who's afraid of schrodinger's cat? All the New Science Ideas You Need to Keep Up with the New Thinking. New York: Morrow \& Co.

National Association of School Psychologists (2003). Position papers. http://www.nasponline.org/information/pospaper_graderetent.html. Retrieved June, 2004.

Phillips, D. C. \& Burbules, N. C. (2000). Postpositivism and educational research. New York: Rowman \& Littlefield Publishers, Inc.

Radford, M. (2006). Researching classrooms: Complexity and chaos. British Educational Research Journal. 32(2), 177-190.

Reilly, D. H. (2003). Non-linear systems and educational development in Europe. Journal of Educational Administration. 37(5), 424-436.

U. S. Department of Education (2002) No child left behind. http://www.ed.gov/nclb/accountability/index.html. Retrieved July 13, 2004.

Waldrop, M. M. (1992). Complexity: The emerging science at the edge of order and chaos. New York: Simon \& Schuster.

\section{About the Author}

Eileen Johnson is an assistant professor in the department of educational leadership at Oakland University where she teaches graduate courses in research methods, learning theory, and philosophy and ethics of leadership. Her current research interests include the application of complexity theory and systems models to educational processes and practice, and understanding the impact of sociocultural influences and disciplinary training on psycho-epistemological style.

(C) Copyright 2008. The author, EILEEN JOHNSON, assigns to the University of Alberta and other educational and non-profit institutions a non-exclusive license to use this document for personal use and in courses of instruction provided that the article is used in full and this copyright statement is reproduced. The author also grants a non-exclusive license to the University of Alberta to publish this document in full on the World Wide Web, and for the document to be published on mirrors on the World Wide Web. Any other usage is prohibited without the express permission of the authors. 